\title{
As Redes Sociais Importam para a Pobreza Urbana?
}

Eduardo Cesar Leão Marques

\section{INTRODUÇÃO}

\begin{abstract}
A s literaturas sociológica e de estudos urbanos recentes têm destacado crescentemente a importância das redes sociais para a sociabilidade urbana e para as condições de vida dos indivíduos. Apesar disso, são relativamente raros os estudos sobre o tema, em especial enfocando conjuntamente os efeitos da segregação residencial e das redes. Como sabemos desde pelo menos o trabalho seminal de Wilson (1987), ambas conformam estruturas de médio alcance que medeiam o acesso dos indivíduos a estruturas de oportunidades. Analisar os efeitos diferenciados dos padrões de relação dos indivíduos em situação de pobreza que habitam locais submetidos a diferentes graus de segregação é o objetivo deste artigo. Baseio-me em pesquisa recente mais ampla, que analisou as redes sociais e a sociabilidade de indivíduos em situação de pobreza em São Paulo (Marques, 2009).
\end{abstract}

A relevância do tema é ao mesmo tempo acadêmica e ligada à construção das políticas sociais (Perri 6, 1997). Por um longo período, a ênfase da literatura e das políticas de combate à pobreza esteve em atributos pessoais dos indivíduos e das famílias em situação de pobreza, tentando dotá-los de características que supostamente seriam estratégicas para que saíssem da pobreza e ascendessem socialmente. Embora outras dimensões tenham sido incorporadas ao longo do tempo, uma

DADOS - Revista de Ciências Sociais, Rio de Janeiro, Vol. 52, nº2, 2009, pp. 471 a 505. 
parte importante das iniciativas públicas continua orientada por esse viés. Essa compreensão "atomista" da pobreza talvez seja explicada pela hegemonia de uma visão (marcada pelo discurso econômico) que foca a existência ou a inexistência de rendimentos monetários ou, no máximo, de ativos individuais entendidos dentro do marco das discussões do capital humano e associados à educação, às boas condições de saúde etc. Segundo essa visão, esses elementos seriam importantes por permitir aos indivíduos acessar mais facilmente, ou com melhores credenciais, estruturas de oportunidades similares às consideradas quando se pensa apenas nos rendimentos. Embora essas dimensões sejam absolutamente essenciais para a compreensão da pobreza e para o seu enfrentamento pelas políticas de Estado, tanto trabalhos acadêmicos quanto as políticas já implementadas demonstram que outros elementos podem também ser fundamentais.

Em período recente, deslocamentos importantes têm ocorrido até mesmo no interior dessa tradição, incorporando o efeito de processos coletivos e sociais. É nessa direção que caminham as discussões sobre os efeitos de vizinhança, os role model effects e os peer group effects, assim como sobre o seu impacto nas situações de privação e pobreza. Embora incorporando elementos supraindividuais, esses deslocamentos não contribuem para o rompimento da visão atomista que marcava a literatura anterior, visto que esses processos são entendidos usualmente como elementos ambientais que influenciam aquelas mesmas propensões e capacidades individuais já citadas, e não como lócus de dinâmicas próprias que impactam as condições sociais.

A consideração da influência dos padrões de relação sobre as situações sociais nos afasta tanto de análises estruturalistas e holistas da pobreza, que derivam essa condição diretamente de dinâmicas estruturais, usualmente da economia e do mercado de trabalho, quanto de perspectivas individualistas e atomistas, que veem a pobreza como simples resultado de atributos individuais e comportamentos e decisões pessoais.

A adoção de uma perspectiva relacional não pretende negar a importância das chamadas condições econômicas objetivas nem das estratégias e dos comportamentos individuais, ambos absolutamente essenciais para a compreensão do fenômeno. No entanto, a integração da sociabilidade e das redes aos constrangimentos econômicos mais amplos e às escolhas individuais permite avançar para a superação da dicoto- 
mia entre estrutura e ação que marca a maior parte das interpretações sobre o tema. Com relação ao conteúdo dos processos mobilizados, por outro lado, esse tipo de análise possibilita a construção de um ponto de partida não apenas econômico para o estudo da pobreza, inserindo essa dimensão nos processos sociais que o cercam.

Neste artigo, exploro as associações entre os padrões de relação e a sociabilidade dos indivíduos e algumas das dimensões mais importantes do acesso a bens e serviços obtidos em mercados: obtenção de trabalho; obtenção de trabalho com alguma proteção; precariedade social; e rendimentos monetários. O trabalho e o rendimento representam os elementos mais comumente associados pela literatura à pobreza, enquanto a precariedade estabelece uma medida síntese das condições sociais negativas, tentando apontar para as situações mais precárias entre os mais pobres. Foram estudadas redes de 209 indivíduos, em situação de pobreza, que habitam sete locais na Região Metropolitana de São Paulo, submetidos a diferentes condições de segregação, além de trinta indivíduos de classe média, entrevistados para gerar um controle da variabilidade do fenômeno.

Vale dizer que a causalidade entre esses elementos é considerada biunívoca; ou seja, as redes influenciam os processos, mas são também impactadas por eles. Assim, a distinção que estabeleço é apenas analítica; em termos ontológicos, tanto atributos individuais e situações sociais quanto redes se produzem e se influenciam mutuamente. A construção de padrões de relação e atributos se dá de forma concomitante e imbricada ao longo das trajetórias de vida dos indivíduos.

O artigo está dividido em quatro seções, além desta introdução. Na primeira, discuto a literatura sobre o tema e construo conceitualmente o objeto analisado. A segunda seção descreve o desenho de pesquisa e as opções analíticas adotadas. Na terceira, são apresentados os resultados alcançados. Na última seção, resumo as principais descobertas.

\section{A POBREZA E AS REDES NA LITERATURA}

A pobreza foi estudada tradicionalmente por investigações centradas em processos estruturais e sistêmicos que derivaram as condições de vida e a pobreza diretamente da especificidade do nosso capitalismo (periférico) ou das dinâmicas dos nossos mercados de trabalho, marcados em especial por desemprego e informalidade. Mais recentemente, em especial desde os anos 1970, o campo se tornou dominado por uma 
literatura focada em atributos individuais, sendo processos e elementos sociais entendidos apenas como constrangimentos à inserção dos indivíduos.

Apesar disso, uma parcela da literatura avançou recentemente ao sugerir a incorporação do espaço (Wilson, 1987; Briggs, 2005), resultando em políticas focadas operacionalmente no território, a fim de enfrentar a crise urbana, como a Politique de la Ville francesa (Le Galès, 1996). De modo concomitante, foram também integrados os efeitos multiplicadores de precariedade social na cidade, sobretudo em termos de cumulatividade de processos negativos e de segregação socioespacial (Briggs, 2003). A introdução desses elementos e a construção de políticas em tal direção representam um avanço que apenas lentamente chega ao Brasil (Torres, 2005; Marques e Torres, 2005). Entretanto, a experiência internacional de políticas e trabalhos acadêmicos recentes (Blokland, 2003) têm demonstrado que apenas a incorporação do local de moradia, entendido como "ambiente", parece não dar conta de todos os desafios a serem enfrentados (Briggs, 2005).

Acredito que, para avançarmos na compreensão da pobreza, é necessária uma mudança de enfoque que supere o paradigma atomista e parta de uma ontologia verdadeiramente relacional, no sentido de Emirbayer (1997) e Tilly (2001). Para isso, temos que trazer as relações para o centro da análise, mesmo que levando em conta os atributos, pois ambos se influenciam dinamicamente de forma contínua. Certo olhar sociológico sobre o tema tem defendido, já há algum tempo, a importância de elementos sociais de natureza coletiva e supraindividual (Massey e Denton, 1993), assim como processos extraeconômicos na produção e na reprodução da pobreza (Paugam, 2005). No contexto dessa perspectiva, a pobreza não seria vista apenas como uma questão de reprodução econômica, mas de integração social e de pertencimento, considerando uma abordagem relacional da pobreza.

No caso brasileiro e latino-americano, marcado por uma herança de estudos mais estruturais sobre o tema (Moya, 2004), essa literatura exerceu uma influência acadêmica razoável, mas não chegou a construir um conjunto de elementos que permitam operacionalizar pesquisas empíricas sobre o assunto, de maneira que testasse a importância dos elementos destacados e cotejasse essa importância com a das variáveis individuais. A presente pesquisa se insere nesse debate, deslocando a ênfase e estudando detalhadamente as principais características das 
redes sociais de indivíduos em situação de pobreza, os seus condicionantes e as consequências desses padrões relacionais para as situações de pobreza urbana encontradas.

A questão é de especial relevância, pois uma geração recente de políticas de combate à pobreza já tem as redes como um dos elementos de interesse ${ }^{1}$. Na verdade, como é amplamente aceito por essa literatura (Policy Research Initiative, 2005a; 2005b), e comprovado por estudos brasileiros, como Pavez (2006), as ações do Estado já impactam as redes sociais de modo não intencional, mas a sua consideração explícita pode ser bastante útil para o desenvolvimento das políticas públicas. Considero que a relação entre redes e políticas envolve basicamente duas formas de interação.

Em primeiro lugar, as redes podem ajudar a melhorar a implementação, tornando as iniciativas públicas mais capazes de alcançar os seus alvos (Trotter, 1999), como no caso da incorporação de associações não governamentais na política brasileira de combate à Aids, hoje referência internacional, ou ajudando a customizá-las a aspectos locais, inclusive culturais, como na contratação de agentes comunitários nas políticas de saúde (Lotta, 2006). Uma segunda linha de importância das redes, entretanto, é menos operacional e mais substantiva. As redes têm sido citadas como um dos elementos que caracterizam a pobreza e que devem ser diretamente impactados pelas ações do Estado (Levitas et alii, 2007; Policy Research Initiative, 2005a; Perri 6, 1997). Esse é o caso de amplo, mas ainda recente, conjunto de políticas de combate à pobreza formuladas a partir do conceito de capital social (Policy Research Initiative, 2005b; Cechi, Molinas e Sabatini, 2008; Perri 6, 1997). Essa geração de políticas já chegou ao Brasil, embora de forma acrítica e sem a menor especificação dos mecanismos associados às redes, tornando a sua citação pouco mais do que um elemento retórico.

A questão de fundo que parece representar um importante obstáculo ao desenvolvimento de políticas que não apenas sejam informadas da existência das redes, mas as incorporem e ajam sobre elas, é que se sabe pouco sobre o fenômeno, assim como sobre a sua contribuição para a reprodução das situações de pobreza. Se quisermos levar às últimas consequências a dimensão relacional da pobreza (Perri 6, 1997), é preciso compreender muito mais detalhadamente os padrões de relação que cercam os indivíduos. O estudo das redes de indivíduos e comunidades, portanto, encontra-se em posição de destaque também em nível 
internacional na interface entre o conhecimento acadêmico e o desenvolvimento de políticas eficazes de combate à pobreza (Policy Research Initiative, 2005a; 2005b).

Embora o destaque das redes sociais nos debates de políticas seja recente, a sua presença é mais antiga na produção acadêmica de ciências sociais. A preocupação já se fazia presente na ontologia social considerada por clássicos da sociologia, como Simmel (1972) [1908], e foi objeto de atenção destacada em estudos diversos ao longo dos últimos trinta anos. Os debates das redes sociais e pessoais se associam (ou podem se associar) ao tema da pobreza, permitindo incorporar simultaneamente elementos mais gerais da estrutura social e a sociabilidade cotidiana dos indivíduos. Vale adiantar aqui que as redes são exploradas como elemento importante na promoção tanto de coesão social (bonding) quanto na construção de conexões e de integração social (bridging), no sentido dado aos termos por Briggs (2001). O primeiro efeito pode auxiliar na produção de identidades, na promoção de sensação de pertencimento e na construção de controle social nas comunidades. O segundo efeito tem consequências sobre a integração social, a redução do isolamento de grupos sociais específicos e a construção de padrões de sociabilidade com troca e integração mais intensa entre grupos. Tanto redes sociais quanto redes pessoais produziriam potencialmente coesão e integração.

Assim, as redes dos indivíduos devem ser incorporadas necessariamente aos nossos modelos explicativos da reprodução da pobreza, se pretendemos considerá-la de forma relacional e multidimensional (Mingione, 1996; Levitas et alii, 2007). Nesse sentido, uma ampla literatura tem citado a conexão entre redes e o que Lin (1999) denomina realização de status ao longo do ciclo de vida - a aquisição de características individuais que são construtoras de hierarquias sociais, como rendimento, escolaridade, cultura etc. Segundo essa concepção, diversos processos e atributos sociais dependeriam da existência de um tipo específico de capital social composto de elementos coletivos produzidos e estocados acima do nível dos indivíduos, mais precisamente nas suas teias de relações (Perri 6, 1997). Para os autores que tentam conectar o capital social às redes, as características comportamentais destacadas pela literatura, como confiança mútua e civismo (a partir de Putnam, 1996), seriam geradas e reproduzidas pelas redes de relações. Sugere-se que "capital social se refere às redes de relações sociais que podem prover aos indivíduos e grupos o acesso a recursos e apoio" (Pol- 
icy Research Initiative, 2005b:5; tradução do autor). Esse elemento é destacado por uma parte importante dos diagnósticos internacionais recentes do tema (Policy Research Initiative, 2005a; 2005b; Cechi, Molinas e Sabatini, 2008; Perri 6, 1997; Levitas et alii, 2007).

Adicionalmente, a análise de redes também pode ajudar a refinar o nosso entendimento sobre os efeitos da segregação territorial sobre a pobreza, outro tema já bastante investigado pela literatura (Wilson, 1987; Jargowsky, 1997; Briggs, 2001). Nesse particular, apenas estudos empíricos que trabalhem conjuntamente espaço e redes podem ajudar a avaliar em que medida as redes integram locais segregados, conectando os indivíduos submetidos a essa condição a contextos sociais mais amplos. Em termos gerais, o problema remete às relações entre a estrutura social, a localização geográfica e a estrutura relacional do social composta pelas redes. De maneira mais específica, a questão diz respeito aos acessos desiguais que os indivíduos podem ter a bens materiais oriundos de serviços, políticas e mercados de trabalho ou a elementos imateriais, como repertórios e formas de viver. Nesse sentido, as redes poderiam ajudar a vencer espaços geográficos e sociais e dar acesso aos indivíduos a círculos sociais mais ou menos amplos, ou inseri-los nesses círculos. Assim, embora com sinais trocados, tanto as redes sociais quanto a segregação apareceriam como estruturas de acesso diferenciado às oportunidades presentes em uma dada sociedade; e, a partir das quais, no entender da literatura sobre pobreza, os indivíduos apresentariam as suas credenciais (ou ativos) e retirariam renda dos mercados.

\section{A PESQUISA}

O estudo levantou as redes pessoais de 209 indivíduos em situação de pobreza e de trinta indivíduos de classe média a fim de construir um padrão de comparação. Para explorar os efeitos da segregação espacial sobre as redes pessoais, foram escolhidos sete locais bastante distintos do ponto de vista da inserção urbana, partindo de estudos anteriores sobre a distribuição espacial dos grupos sociais em São Paulo. Foram levantadas aproximadamente trinta redes pessoais em cada local estudado, além do grupo de controle de classe média, sem especificação de local de moradia. Na verdade, se controlássemos a localização residencial da classe média, encontraríamos um padrão concentrado no centro expandido da metrópole, embora as suas redes se expandam por um amplo território e não incluam praticamente nenhum indivíduo da sua 
vizinhança física, em um padrão similar ao que Wellman (2001) denomina comunidades pessoais. Esse padrão é muito distinto do encontrado entre indivíduos em situação de pobreza, o que já indica enormes diferenças nos padrões de relação e nas possibilidades de utilização dessas relações.

Optei por analisar redes pessoais, e não redes de comunidades ou redes egocentradas em indivíduos. Diferentemente da maior parte da literatura internacional, considero que uma parcela importante da sociabilidade que influencia a pobreza e as condições de vida ocorre a distâncias maiores do ego do que do seu entorno imediato ${ }^{2}$, razão pela qual são levantadas aqui as redes totais dos indivíduos, sem limitar previamente o seu tamanho. Essa decisão se mostrou muito acertada, pois as redes encontradas na pesquisa variaram entre cinco e 148 indivíduos (cada qual representado posteriormente por um nó na rede). Essa variabilidade de situações relacionais não teria sido captada pela consideração apenas das redes egocentradas.

Os locais estudados resultaram de uma amostra intencional das localizações de indivíduos em situação de pobreza na cidade do ponto de vista da distância ao centro, dos graus de consolidação das áreas, dos padrões construtivos e dos graus de intervenção do Estado. Entre os locais estudados, a localização mais central inclui cortiços no Centro da cidade. As localizações mais segregadas e distantes incluem uma favela na franja periurbana da Região Metropolitana, um conjunto habitacional de grande porte na franja urbana da Zona Leste do município de São Paulo e uma área bastante periférica na Zona Sul. Além dessas, foram pesquisadas redes pessoais em duas favelas de grande porte com localizações relativamente próximas ao centro expandido, uma contígua a um bairro de renda extremamente alta, e outra contígua a bairros de classes média e alta. Uma terceira favela de pequeno porte, próxima ao centro de um município periférico e inserida em um distrito industrial, completa o conjunto estudado. As entrevistas foram realizadas em dias de semana e em fins de semana entre setembro de 2006 e agosto de 2007.

Em cada um desses locais, foram realizadas entrevistas com um questionário semiaberto e um gerador de nomes. A escolha dos entrevistados em cada campo ocorreu de forma aleatória ao longo de percursos pelos locais estudados, sendo os indivíduos abordados nos espaços públicos ou na entrada das suas casas. Em alguns casos, o acesso aos lo- 
cais de estudo foi mediado por informantes de pesquisas anteriores ou membros dos movimentos associativos locais. Ao longo do trabalho de cada campo, a amostra de entrevistados foi controlada por alguns atributos sociais básicos, como sexo, idade, status migratório e ocupacional, e área de moradia no local estudado. Esse controle objetivou garantir uma proporcionalidade razoável com as características médias da população local e evitar a constituição de vieses. A comparação entre as características dos entrevistados e da população estudada sugere que esse objetivo foi alcançado com bastante sucesso.

A classe média foi definida de maneira ampla, mesclando critérios de rendimento com ocupação, e inclui profissionais liberais, funcionários públicos, pessoas envolvidas com atividades intelectuais e donos de estabelecimentos comerciais de certo porte. A delimitação do grupo não seguiu maiores preocupações conceituais ou metodológicas, visto que o objetivo das entrevistas com indivíduos assim classificados era apenas constituir um padrão de comparação para a análise das redes de indivíduos em situação de pobreza. As informações das redes de classe média, portanto, foram usadas apenas como parâmetro e nunca em análises mais centrais e conclusivas.

Essas informações foram posteriormente tratadas com ferramentas de análise de redes sociais, resultando em 239 redes pessoais. Em seguida, explorei diversas características das redes dos indivíduos em situação de pobreza, acessando os seus principais condicionantes e os processos que influenciam na sua formação e dinâmica, comparadas com as redes de classe média. Foram estudados os processos de criação e rompimento de vínculos, as dinâmicas da homofilia ${ }^{3}$ e os condicionantes sociais de construção e manutenção de redes. As redes variam segundo diversos atributos e variáveis específicas, incluindo sexo, ciclo de vida, status migratório e ocupacional, entre outras. De forma geral, praticamente inexistem relações dos indivíduos com pessoas de grupos sociais e de renda diferentes dos seus. Essa é talvez uma das mais importantes características dessas redes para a reprodução da pobreza e da desigualdade social. Naturalmente, a questão não se origina nas redes, mas representa apenas uma faceta relacional da estrutura social.

Em seguida, e já com as análises estatísticas realizadas, escolhi um conjunto de redes pessoais para empreender a parte qualitativa da pesquisa. Os critérios para a escolha dos casos combinaram os tipos de rede encontrados, os campos estudados e as características pessoais dos en- 
trevistados. Ao todo foram realizadas entrevistas qualitativas com vinte indivíduos, explorando as transformações das redes desde as primeiras entrevistas, assim como a sua utilização pelas pessoas no cotidiano, como na migração, na obtenção de emprego, em ajudas com relação à saúde e a cuidados com as crianças, na habitação, na obtenção de empréstimos de vários tipos, no acesso a apoio emocional e a políticas públicas, entre outros tipos de auxílio. Essas informações me permitiram compreender a dinâmica dos padrões relacionais e a sua mobilização pelos indivíduos. Os padrões e as recorrências observados me levaram a delimitar mecanismos sociais responsáveis tanto pela constituição e transformação das redes quanto pela sua mobilização pelos indivíduos nas suas práticas.

O presente artigo apresenta a parcela da pesquisa relativa à análise quantitativa das consequências das redes para a situação social dos indivíduos, em especial de pobreza, sendo o leitor remetido a Marques (2009) para a parte qualitativa e a discussão dos mecanismos.

\section{RESULTADOS}

Os resultados apresentados ao longo desta seção se referem aos testes empíricos da importância das redes para o acesso a bens e serviços obtidos em mercados que influenciam a pobreza e as condições de vida. Alguns resultados anteriores da pesquisa, entretanto, devem ser reportados a seguir para que se compreendam as dimensões discutidas.

Em primeiro lugar, os resultados demonstraram que, quando comparadas com as redes de classe média, as redes pessoais de indivíduos pobres tendem a ser menores, mais locais e menos variadas em termos de sociabilidade. Apesar disso, elas variam substancialmente entre si, sendo bastante difícil encontrar relações diretas entre variáveis socioeconômicas e padrões de relação. Os principais efeitos de condicionantes socioeconômicos sobre as redes são os que se seguem. Apenas a título de exemplo, apresento a seguir os sociogramas das redes de uma mulher pobre, moradora de um conjunto de periferia, e de uma mulher de classe média. Ambas são casadas e apresentam indicadores próximos da média de cada grupo.

Embora tenhamos trabalhado com indivíduos no interior da pobreza, os dados mostraram que os mais pobres entre os pobres têm redes com menor variabilidade da sociabilidade, localismo mais elevado e maior importância da vizinhança. De forma geral, esses resultados apontam 
Figura 1

Sociograma da Entrevistada 164

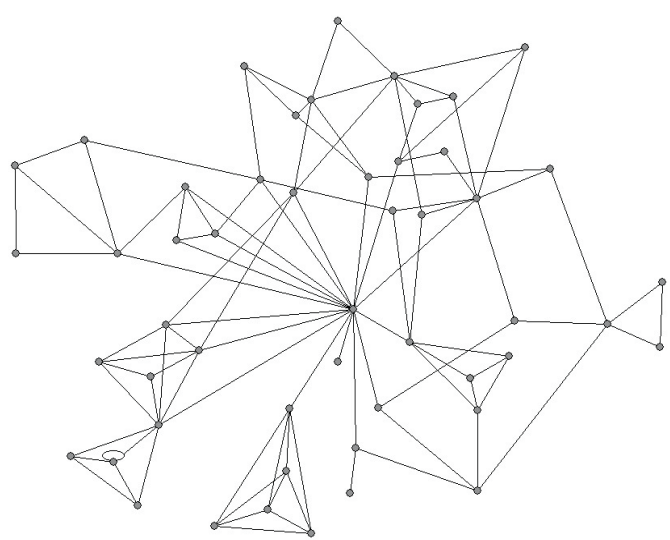

Elaboração própria a partir de material empírico coletado.

Figura 2

Sociograma da Entrevistada 93

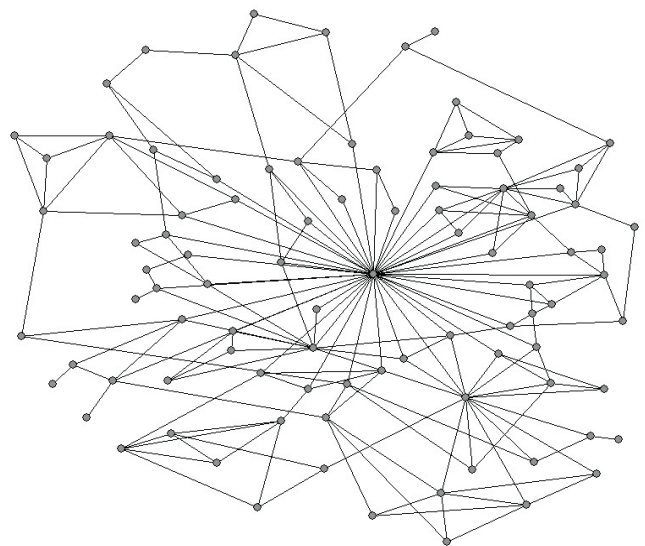

Elaboração própria a partir de material empírico coletado.

para a dificuldade que os indivíduos mais pobres têm de fazer frente aos custos de constituir e manter vínculos. A escolaridade tem aparentemente um efeito similar, embora independente, mesmo que controlada pela renda. Indivíduos com escolaridade mais elevada, mesmo entre os mais pobres, tendem a ter redes mais ricas e menos locais em termos de vínculos, reforçando a ideia, presente na literatura internacional, que atribui um papel importante ao ambiente escolar na construção de vínculos sociais diversificados. A existência dessas duas dinâ- 
micas combinadas (visto que renda e escolaridade se encontram altamente correlacionadas) cria provavelmente importantes efeitos de circularidade na perpetuação da situação social e relacional dos mais pobres, com consequências importantes não apenas para a pobreza mas também para a desigualdade social. Padrões relacionais diferentes e atributos distintos tendem a construir o tipo de reforço que caracteriza as "desigualdades persistentes", embora nesse caso não sejam necessariamente desigualdades categoriais, considerando o sentido de Tilly (2005).

Em consonância com o descrito pela literatura internacional, o ciclo de vida apresenta importantes efeitos sobre as redes (Bidart e Lavenu, 2005; Blokland, 2003), embora no nosso caso os resultados apareçam sobretudo nos dois extremos da estrutura etária. A velhice tende a reduzir as redes e a torná-las menos ricas, em termos de sociabilidade, mais locais e mais centradas na família. Os jovens, por outro lado, não têm redes substancialmente diferentes dos demais indivíduos (ao contrário do que sustenta a literatura), mas têm uma sociabilidade mais centrada nos estudos e na amizade, além de redes mais locais do que a média da amostra estudada. A análise posterior dos tipos de rede sugeriu ainda que idosos e jovens estão associados a duas situações relacionais típicas, com, respectivamente, tamanhos muito pequeno e bastante grande, mas ambas com sociabilidade local e bastante homofílica.

Embora a pequena participação dos indivíduos em associações não nos permita concluir o seu efeito sobre as redes, a frequência a templos (e não a adesão a credos religiosos) tem efeitos sobre as redes. As pessoas que frequentam intensamente templos religiosos (mais do que quinzenalmente) tendem a ter maior diversidade de sociabilidade, mesmo quando as diferenças são controladas pelo rendimento. $\mathrm{O}$ efeito tende a desaparecer quando controlado pela sociabilidade (e não pela renda), o que nos impede de separar completamente os dois efeitos.

O sexo dos indivíduos tende a não produzir efeitos significativos sobre as redes, embora haja evidências não conclusivas de que as mulheres tenham redes um pouco maiores, menos associadas à família, ao trabalho e ao lazer. A aquisição de nós por redes e na igreja é mais frequente para as mulheres; a de contexto familiar, para os homens. Quando se consideram apenas homens e mulheres que trabalham, as redes das mulheres se apresentam maiores. Essa diferença se mantém quando se comparam homens e mulheres que trabalham fora da comunidade, embora as diferenças de sociabilidade desapareçam, sugerindo que as 
diferenças talvez não se liguem a sociabilidades distintas em si, mas a diferentes inserções sociais nas esferas pública e privada que os mercados de trabalho possibilitam. Esses resultados confirmam os apresentados por Moore (1990) para o contexto norte-americano usando redes egocentradas.

Também não foram encontradas diferenças organizadas segundo o status migratório, nem mesmo quando se consideram separadamente migrações recente e antiga, embora a proporção de conterrâneos vá diminuindo com o tempo. Na verdade, as principais diferenças aparecem quando delimitamos um subgrupo de migrantes que têm muitos conterrâneos nas suas redes. As redes desses indivíduos são menores e menos variadas socialmente. Nesses casos, tratava-se da presença de conterrâneos conformando verdadeiras comunidades transplantadas (por vezes de locais muito pequenos, sendo a vizinhança mantida no local estudado em São Paulo), de forma similar ao que foi discutido por Portes (1999), Maya Jariego (2003) e Dujisin e Maya Jariego (2005). Os resultados da análise dos condicionantes da precariedade social comentados mais adiante reforçam esses achados.

Por fim, confirmando resultados prévios presentes na literatura, a relação entre espaço urbano e redes indicou que as redes de indivíduos pobres são marcadas por intenso localismo. No caso da classe média, não há praticamente nenhum localismo ou vizinhos nas redes, e a própria ideia de comunidade ou de dentro/fora não faz nenhum sentido. Os indivíduos de classe média constroem suas redes em espaços geográficos muito mais amplos, incluindo laços por toda a cidade, mas também em outras cidades ou países, em um padrão próximo ao que Wellman (2001) denomina "comunidades pessoais desterritorializadas".

A hipótese inicial de um efeito direto da segregação social no espaço sobre as redes não se verificou, e a segregação (macrossegregação, na escala da cidade) parece não impactar diretamente o tamanho, a atividade e a estrutura das redes. Apesar disso, indivíduos de regiões mais segregadas tendem a ter redes com menor localismo, em especial se o local de moradia é de pequena escala. Assim, se há efeito da segregação sobre as redes, parece operar para tornar a sociabilidade mais ampla em termos urbanos e, talvez, mais diversificada, favorecendo as redes de locais mais segregados.

Portanto, a análise sugere que a relação entre segregação e redes é mais complexa do que a descrita pela literatura e do que a formulada na minha hipótese inicial. Embora as redes não variem substancialmente se- 
gundo o grau de segregação dos locais estudados, aparentemente ajudam a integrar uma parte dos indivíduos que estão segregados. A análise dos condicionantes dos rendimentos comentada a seguir confirma esse achado.

Considerando a variabilidade encontrada nas redes, a estratégia que segui para analisá-las foi a construção de tipologias. Foram construídas duas tipologias utilizando análise de cluster: das redes dos indivíduos pobres (a partir de indicadores das redes) e dos seus padrões de sociabilidade (a partir da distribuição proporcional das redes pelas esferas de sociabilidade). Os achados indicam que, embora as redes de indivíduos em situação de pobreza sejam em geral menores, mais locais e menos variadas do que as de indivíduos de classe média, variam muito, e também se observam redes grandes e de sociabilidade mais variada, assim como redes menores e com isolamento urbano significativo. É interessante destacar que o tamanho, a variabilidade da sociabilidade e o localismo não caminham juntos, e as redes maiores são muito locais. Essa característica também está presente nas redes muito pequenas, sendo as de tamanho médio as que apresentam menor localismo.

No que diz respeito à sociabilidade dos mais pobres, os dados também sugerem a existência de padrões muito diversificados. Se, por um lado, podemos notar a existência de padrões de sociabilidade muito locais e baseados em vínculos primários (basicamente família, vizinhança e amizades), uma parte significativa das redes apresenta sociabilidade pouco local e produzida substancialmente em ambientes organizacionais ou institucionais (trabalho, igreja, associativismo).

O cruzamento dessas heterogeneidades, ao mesmo tempo que confirmou a heterogeneidade das redes, sugeriu a existência de padrões relacionais amplos, com sociabilidade variada e homofilia potencialmente menor, mesmo entre os pobres. Essas situações relacionais se mostraram centrais para a explicação das situações sociais em geral e de pobreza em particular, como veremos a seguir ${ }^{4}$.

\section{Trabalho}

A maior parte dos indivíduos obteve trabalho por contatos através de redes $-66 \%{ }^{5}$. Entretanto, quais são as principais consequências das redes dos indivíduos para os seus trabalhos e até que ponto esse efeito não pode ser creditado a outras variáveis consideradas tradicional- 
mente pela literatura? No teste que se segue, utilizei medidas de rede e incluí como "com trabalho" os indivíduos empregados com e sem carteira, domésticos ou não (74 casos), assim como os pequenos proprietários (17 casos) e os trabalhadores em negócios familiares (apenas três casos $)^{6}$. Considerando as características das atividades declaradas como trabalho autônomo, julguei esses casos como representando desemprego oculto, somando-os ao desemprego na conformação dos "sem trabalho"7. Os indivíduos com trabalho totalizavam 94 (45\% dos entrevistados), contra 57 indivíduos sem trabalho (27\%) e outros $58(28 \%)$ em que não se aplicavam as condições (donas de casa, aposentados e estudantes).

Primeiramente, para avaliar a associação entre a condição "ter trabalho" e as redes, procedi a testes de análise de variância com medidas de rede separadamente. Os resultados indicam que a variabilidade da sociabilidade dos indivíduos e o localismo têm efeitos significativos ${ }^{8}$, sendo que as redes dos com trabalho tendem a ser levemente mais locais e a ter sociabilidade mais variada. $\mathrm{O}$ tamanho e outras medidas das redes não apresentam associação com a condição de trabalho.

Os tipos de rede, por outro lado, não apresentam efeito direto sobre o status de estar empregado ${ }^{9}$. No que diz respeito à sociabilidade, os indivíduos que têm sociabilidade ligada ao trabalho têm maior probabilidade de estarem empregados do que os demais (significativo a 95\% de significância). A causalidade, nesse caso, não é nem um pouco clara, visto que é razoável imaginar que quem tem sociabilidade intensa ligada ao trabalho tem ou teve trabalho em período relativamente recente. Essa é a única sociabilidade que apresenta significância individualmente. Entretanto, indivíduos que têm sociabilidades ligadas a ambientes institucionais - igreja, trabalho e associações - também tendem a estar significativamente mais empregados do que os que têm sociabilidade mais local e primária - família, vizinhança e amizade.

Para analisar o efeito conjunto dos condicionantes sociais e relacionais, utilizei uma técnica exploratória de classificação por árvore conhecida comumente como Chaid. O método estuda basicamente a relação entre uma variável dependente e uma série de variáveis preditoras que interagem entre si, escolhendo sucessivamente as de maior poder explicativo, em uma árvore de associações ${ }^{10}$. Na explicação do status de "ter trabalho", foram utilizadas dezoito variáveis: relacionais, socioeconô- 
Figura 3

Árvore da Explicação do Emprego (Chaid)

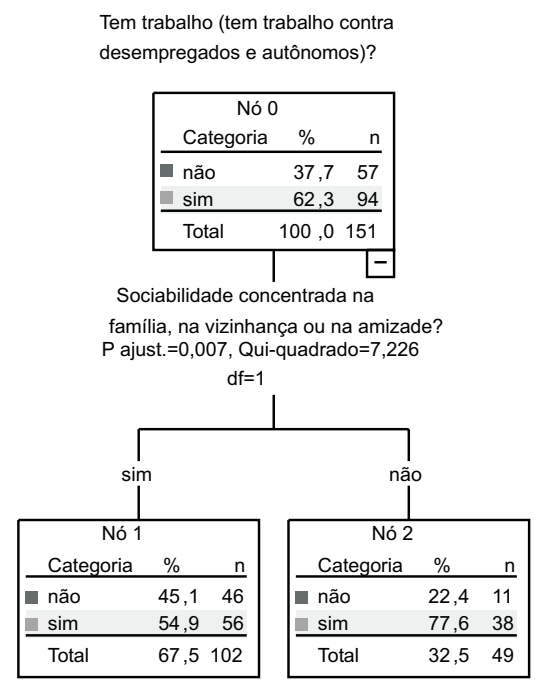

Elaboração própria a partir de material empírico coletado.

micas, etárias, migratórias e espaciais ${ }^{11}$. A Figura 3 acima apresenta a informação.

O resultado indicou o tipo de sociabilidade dos indivíduos como o que mais diferencia as situações de ter ou não trabalho, sugerindo que sociabilidades mais primárias e mais tendentes à homofilia - família, vizinhança e amizade - tendem a gerar piores situações com relação a trabalho. O resultado é evidentemente o mesmo com as sociabilidades com ênfase em ambientes institucionais - igreja, trabalho e associações - , que representam o complemento das anteriores. O modelo explicou corretamente $62,3 \%$ dos casos.

Como podemos ver, a incidência de trabalho é de $62 \%$ no conjunto dos casos considerados (desconsiderando-se os aposentados, donas de casa e estudantes), mas alcança $78 \%$ entre os indivíduos com sociabilidades menos primárias e apenas 55\% entre os com sociabilidades mais primárias e mais locais. Entre quem não tem esse último tipo de sociabilidade, apenas $22 \%$ não tem trabalho, contra $45 \%$ entre as pessoas com sociabilidades concentradas na família, na vizinhança e na amizade. Portanto, a análise indica a importância de os indivíduos terem sociabilidades pouco homofílicas para o acesso a trabalho. É importante notar que os tipos de sociabilidade aparecem como mais importantes 
mesmo na presença de variáveis socioeconômicas consideradas clássicas nas discussões sobre o tema, como a escolaridade, a renda, a idade, o status migratório e o grau de segregação residencial a qual estão submetidos os indivíduos. Como já discutido anteriormente, a causalidade presente aqui é provavelmente múltipla, e os indivíduos tanto têm esse tipo de sociabilidade porque têm trabalho com mais frequência quanto têm trabalho por terem esse tipo de sociabilidade. O caminho mais profícuo para compreendermos essa associação não é a busca de uma direção causal única, mas o estudo dos efeitos dos mecanismos ao longo das trajetórias dos indivíduos (Marques, 2009).

\section{Trabalho Protegido}

Os indivíduos podem ter ou não trabalho, mas esse pode ter qualidade muito diferenciada do ponto de vista da estabilidade e da proteção em termos tanto de acesso a benefícios sociais quanto de certa estabilidade do vínculo no tempo. Para testar o efeito das redes sobre a obtenção de trabalhos de melhor qualidade, dividi os trabalhos em "trabalho protegido" - empregado com carteira (doméstico ou não), proprietário e empregado em negócio familiar - e em "trabalho pouco protegido" - empregados sem carteira, autônomos e desempregados ${ }^{12}$. Essa condição envolvia $41 \%$ dos entrevistados, ou 59 casos, no conjunto de 145 casos $\operatorname{considerados}^{13}$. Aposentados, donas de casa e estudantes foram retirados da análise (31\% do universo).

A análise indicou que nenhuma das medidas e dos tipos de rede influencia diretamente a obtenção de trabalho protegido. Por outro lado, novamente indivíduos com sociabilidade proporcionalmente maior em instituições, menos local e menos primária apresentaram maior probabilidade de ter emprego protegido do que os demais. Entre os indivíduos com esse tipo de sociabilidade, $58 \%$ têm trabalho protegido, contra $33 \%$ dos que têm sociabilidades mais locais e primárias ${ }^{14}$. Esse resultado voltou a aparecer para alguns tipos de sociabilidade separadamente.

Com relação às sociabilidades, os indivíduos com sociabilidade caracterizada pela vizinhança tendem a ter trabalho protegido menos frequentemente - apenas 30\% -, enquanto no restante dos casos essa proporção chega a $46 \%$. A sociabilidade ligada ao trabalho também se apresenta significativa para a associação com trabalho protegido e quem tem essa sociabilidade tem trabalho protegido em $66 \%$ dos ca- 
Figura 4

Árvore da Explicação do "Trabalho Protegido" (Chaid)

Tem trabalho protegido (com

carteira, proprietário e negócio familiar)?

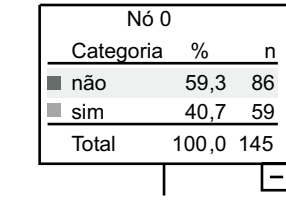

Sociabilidade concentrada na

igreja ou no trabalho?

$P$ ajust. $=0,005$, Qui-quadrado $=7,713$

$\mathrm{df}=1$

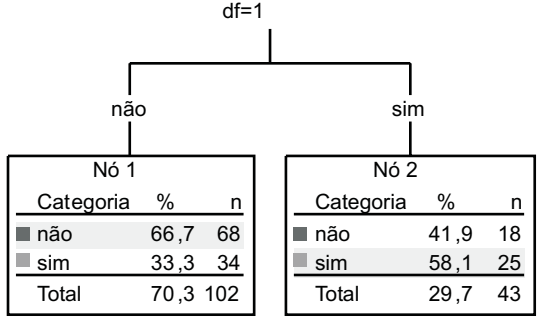

Elaboração própria a partir de material empírico coletado.

sos, contra $34 \%$ de quem tem outros padrões de sociabilidade. No entanto, como já destacado, o sentido da causação não é claro.

Para a análise conjunta dos condicionantes do trabalho mais protegido, foi utilizada a mesma técnica de Chaid ${ }^{15}$. A Figura 4 acima apresenta a informação.

Como resultado, a técnica separou os indivíduos com sociabilidades na igreja ou no trabalho dos demais (a sociabilidade do trabalho também apresentou significância separadamente, mas menos destacada). O modelo explicou corretamente $64 \%$ dos casos.

Conforme podemos ver, a incidência de trabalho protegido é de apenas $41 \%$ dos indivíduos que participam do mercado de trabalho, mas chega a alcançar $58 \%$ entre quem tem sociabilidade na igreja e no trabalho, e apenas $33 \%$ entre quem tem outros tipos de sociabilidade. Portanto, de forma similar à análise anterior, mesmo na presença de variáveis socioeconômicas clássicas, como anos de estudo, status migratório, estrutura etária e renda, a dimensão que mais discrimina os indivíduos que têm trabalho protegido dos que não têm é a que indica a existência de um padrão de sociabilidade pouco primária e potencialmente menos homofílica. 


\section{Precariedade Social}

Podemos analisar também de que forma as redes influenciam a presença de situações de precariedade social em geral. Foi considerada "precária socialmente" a situação em que o entrevistado apresentava ao menos duas condições de precariedade entre quatro - familiar, habitacional, de renda e de trabalho. Aproximadamente um terço dos entrevistados $-31 \%$, ou 64 casos - se encontrava nessa condição, mas a distribuição das condições desagregadas de precariedade variava bastante - apenas $12 \%$ na familiar, $16 \%$ na habitacional, $29 \%$ na relativa aos rendimentos e $60 \%$ na precariedade do trabalho.

Embora as situações de precariedade não encontrem associação direta com características e tipos de rede, os tipos de sociabilidade voltaram a apresentar relevância na mesma direção das análises anteriores. Em primeiro lugar, indivíduos com sociabilidade centrada na vizinhança se mostraram mais sujeitos à precariedade - a precariedade incidia sobre $46 \%$ de pessoas com essa sociabilidade, enquanto sobre apenas $23 \%$ dos que tinham outros padrões de sociabilidade. Em sentido oposto, ia novamente a sociabilidade do trabalho; entre os indivíduos com esse padrão, apenas $12 \%$ eram precários, contra $34 \%$ dos restantes. Um resultado similar e mais precário foi obtido com os indivíduos com sociabilidade primária e local - família, vizinhança e amizade. Entre quem tinha sociabilidade mais primária, 38\% era precário, contra $15 \%$ entre quem tinha outros tipos de sociabilidade. Portanto, quanto mais local e primária a sociabilidade, maior a probabilidade de o indivíduo se encontrar em situação social precária. Contrariamente, para os indivíduos cuja sociabilidade inclui parcelas importantes que ocorrem em ambientes institucionais, a probabilidade de precariedade se reduz ${ }^{16}$.

Os tipos de rede conjuntamente não apresentaram influência na precariedade, mas as redes entre médias e pequenas tendem a estar associadas menos frequentemente a precariedade. Entre os indivíduos com esse padrão de vínculos, $21 \%$ é precário, contra $36 \%$ dos restantes.

As análises indicaram ainda que indivíduos com redes médias e sociabilidade pouco local e pouco primária tendiam a estar menos sujeitos a situações de precariedade do que os demais: apenas $11 \%$ dos indivíduos com esses padrões relacionais apresentam precariedade, contra $35 \%$ de precários com as demais situações relacionais. 
Para a análise conjunta dos condicionantes da precariedade social, foi utilizada novamente a técnica de Chaid com dezessete variáveis: relacionais, socioeconômicas, etárias, migratórias e de trabalho ${ }^{17}$. Como a variável de precariedade foi construída por escolha direta dos casos a partir da renda, da estrutura familiar e da posição na ocupação, essas variáveis evidentemente não puderam ser incluídas no modelo, caso contrário os resultados obtidos seriam tautológicos. O mesmo ocorreu com a variável segregação. Como na construção da precariedade está incluída a segregação habitacional, e como essa é muito mais elevada nos cortiços, a relação entre segregação e precariedade seria forçada pelo método. Por outro lado, variáveis relativas ao trabalho, que antes não foram utilizadas, foram introduzidas aqui.

Como resultado, o método indicou três variáveis e o modelo ajustado explicou corretamente $69 \%$ dos casos. Aárvore resultante é a que se segue (Figura 5).

Figura 5

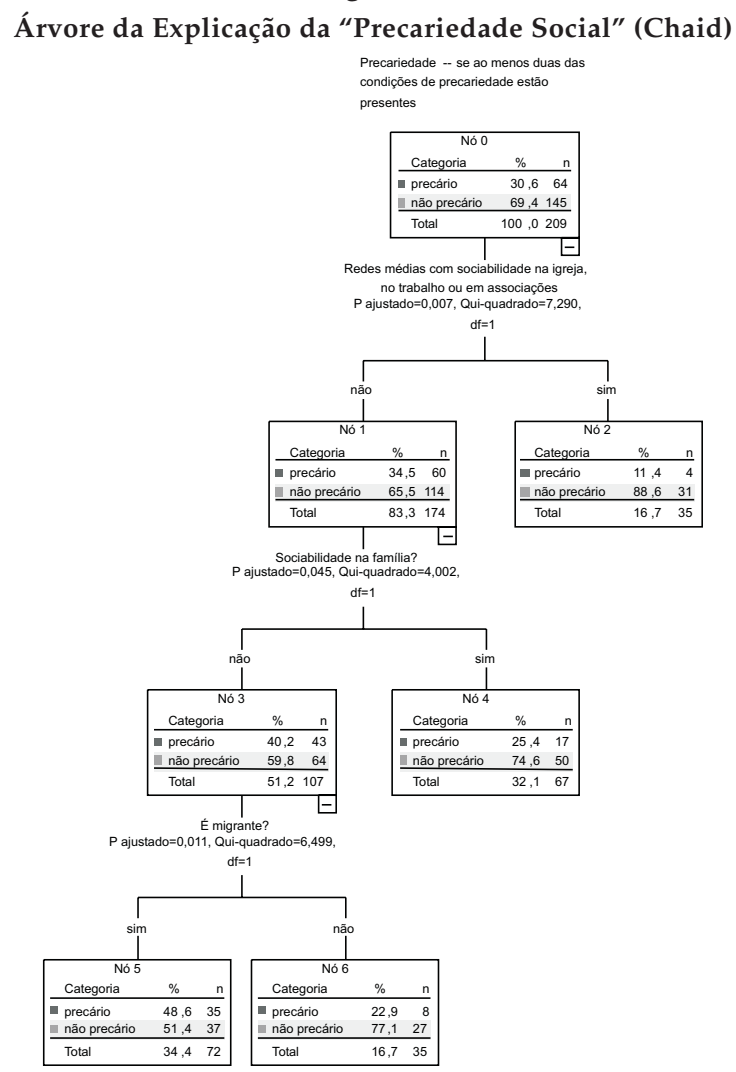

Elaboração própria a partir de material empírico coletado. 
Novamente os resultados foram obtidos mesmo na presença de diversas variáveis socioeconômicas mais tradicionais, como anos de estudo, idade e tempo de migração. Como se pode ver, a precariedade incide sobre $31 \%$ dos casos, mas, entre os indivíduos com redes médias e sociabilidade pouco local ou primária (igreja, trabalho e associações), cai para um terço - $11 \%$. Entre quem não tem esse padrão relacional, por outro lado, a precariedade incide sobre $35 \%$ dos casos. Esses resultados reforçam os anteriores, indicando a sociabilidade nas redes como um dos principais condicionantes das situações sociais dos indivíduos em pobreza.

Entretanto, a segunda linha indica que, entre os indivíduos com sociabilidade mais local e primária, quem tinha sociabilidade centrada na família tendia a ter situação menos precária. Os indivíduos com essa sociabilidade tinham, em média, precariedade de $25 \%$, alcançando $40 \%$ entre os que não tinham nem o padrão relacional do primeiro nível da árvore nem a sociabilidade centrada na família. Embora haja em parte aqui um efeito de método, já que a precariedade inclui uma dimensão familiar, o resultado aponta de forma eloquente para o papel da família na redução da precariedade em indivíduos que não contam com as sociabilidades menos homofílicas.

Esse resultado pode parecer contraditório, pois a concentração da sociabilidade na família, para o conjunto das pessoas estudadas, tende a estar associada mais frequentemente à precariedade social, visto que essa situação está incluída no lado esquerdo do primeiro nível da árvore (34,5\% em situação precária, na média). Entretanto, entre os indivíduos que não contam com redes médias e sociabilidades menos homofílicas e menos locais, os que têm apoio familiar conseguem reduzir relativamente o risco de cair na precariedade (segundo nível da árvore), mesmo que não no mesmo patamar dos que apresentam a sociabilidade anterior (25,4\% contra $11,4 \%)$. Os vínculos familiares, na verdade, estão associados à prestação de ajuda para a solução de problemas cotidianos e para o acesso a bens e serviços providos fora de mercados (Marques, 2009).

Por fim, entre os indivíduos nessa situação (sem a combinação do primeiro nível e sem sociabilidade familiar), a migração aparece como elemento discriminador. A situação dos migrantes com esse padrão relacional era a pior de todas, com a precariedade incidindo sobre quase a metade dos indivíduos (49\%), enquanto entre os não migrantes fora 
das condições analisadas anteriormente chegava a apenas $23 \%$. A princípio, seria possível sustentar, com base nesse resultado, a existência de dimensões de preconceito no mercado de trabalho ou em outras esferas sociais que levassem os migrantes a piores situações em termos de precariedade.

Entretanto, a análise mais detalhada das informações sugere que o modelo está delimitando, na verdade, um grupo específico de indivíduos com baixa integração social. Embora o tempo de migração não apresente associação com o fenômeno, a observação das redes dos indivíduos classificados pelo modelo na pior condição indica uma presença muito grande de conterrâneos. Isso sugere que estão nessa condição sobretudo as pessoas migrantes que experimentaram baixa integração relacional em São Paulo, mesmo que tenham chegado à cidade há muito tempo. Esse efeito não pode ser explicado simplesmente pela presença de preconceitos, visto que outros migrantes apresentam baixa presença de conterrâneos (e não estão localizados majoritariamente na última casela do modelo). Na verdade, os espaços estudados disponibilizam contingentes significativos de indivíduos para a constituição de relações que, mesmo que sejam socialmente homofílicas, podem envolver não conterrâneos em grandes quantidades. Vale acrescentar que a incidência de precariedade entre os indivíduos com sociabilidade mais homofílica, mas não na família e não migrantes (casela à direita na terceira linha da árvore), é similar à incidente entre os com sociabilidade centrada na família (casela à direita na segunda linha da árvore), reforçando a interpretação anterior sobre a baixa integração de uma parte dos migrantes (22,9\% contra 25,4\%). Essa situação está associada a um mecanismo relacional específico que envolve os locais de chegada dos migrantes à cidade (Marques, 2009).

De forma geral, portanto, o resultado indica que a proteção contra a precariedade depende, de maneira combinada, de três formas distintas de apoio social: padrões relacionais pouco locais e pouco primários (com baixa homofilia); esferas familiares ativas na sociabilidade; e maior integração social dos não migrantes que não contam com as dimensões anteriores (relacionais e familiares). Vale especificar que, como o modelo é hierárquico, a importância da sociabilidade na família aparece apenas atenuando a precariedade em quem não tem padrões de relação pouco homofílicos e pouco locais. A presença desses é o elemento mais fortemente associado com situações de baixa precariedade social. 


\section{Rendimentos}

Por fim, analisei os efeitos das redes e de atributos sobre os rendimentos dos indivíduos. Assim como nas análises anteriores, os indivíduos de classe média não estão incluídos nesse teste ${ }^{18}$. A realização da análise que se segue apenas com os pobres a torna bastante robusta, visto que a variação da renda dos indivíduos está limitada pela própria escolha dos casos. É provável, portanto, que, se estivéssemos trabalhando com grupos sociais que abarcassem uma faixa mais ampla de renda, as relações encontradas fossem ainda mais fortes, mas talvez outras variáveis também apresentassem importância. Consequentemente, a análise é bastante rigorosa para explicar a variação dos rendimentos entre os pobres, mas pouco nos informa sobre o que acontece com o fenômeno para o conjunto da sociedade. Foram testadas associações com a renda familiar per capita e com a renda total.

Entre os elementos relacionais analisados individualmente, apenas a variabilidade da sociabilidade, medida pelo número de esferas, tem efeito direto sobre a renda para o conjunto dos casos. Como veremos a seguir, entretanto, outras características das redes podem exercer efeito importante sobre conjuntos de casos específicos.

Os tipos de rede não apresentaram associação com a renda, mas ficou evidenciada a associação com certos tipos de sociabilidade. Os indivíduos com sociabilidade baseada na vizinhança tenderam a apresentar rendas menores - quem tem sociabilidade desse tipo tem em média renda de $R \$ 210$ contra $R \$ 300$ da média dos indivíduos com outros tipos de sociabilidade. Inversamente, quem tem sociabilidade organizacional (igreja, trabalho e associativismo) tende a ter renda substancialmente mais alta - $R \$ 390$ per capita contra $R \$ 225$ de quem tem sociabilidade local e primária. Por fim, pessoas com redes médias com sociabilidade organizacional (a situação relacional que apresenta menos precariedade, como vimos na última seção) têm rendas ainda maiores $\mathrm{R} \$ 430$ contra $\mathrm{R} \$ 240$ das demais situações relacionais ${ }^{19}$. De forma geral, portanto, quanto mais diversificada, menos primária e local for a sociabilidade, maiores tendem a ser os rendimentos.

Como é usual nesse tipo de análise, as medidas de rede e os diversos indicadores sociais se encontram correlacionados. Assim, de que maneira essas variáveis e outros indicadores sociais influenciam conjuntamente na renda? Para analisar de forma combinada as influências das variáveis sociais e dos indicadores de rede sobre a renda, procedi a 
uma série de análises multivariadas utilizando modelos GLM (General Linear Model) ${ }^{20}$.

Após a realização de uma série de testes incluindo variáveis socioeconômicas, de sociabilidade e de redes, cheguei ao modelo que se segue ${ }^{21}$ (Tabela 1). Resultados muito similares foram obtidos com a renda familiar, em vez da renda familiar per capita no modelo, embora com explicação menor. Como não estou interessado em prever resultados, mas apenas em avaliar a influência conjunta dos processos e das variáveis sobre a renda, o resultado pode ser considerado amplamente satisfatório ${ }^{22}$.

As primeiras colunas apresentam os parâmetros; a última, o efeito em reais da variação de uma unidade em cada variável, no nível da renda familiar média per capita de $\mathrm{R} \$ 271$.

Como podemos ver, apresentaram significância estatística na explicação da renda familiar per capita variáveis tradicionais, como a escolaridade do indivíduo e o tamanho do núcleo familiar (pessoas no domicílio). A primeira variável influencia positivamente o rendimento e,

Tabela 1

Resultados do Modelo GLM da Renda Familiar per capita (raiz quadrada)

\begin{tabular}{|c|c|c|c|c|c|c|}
\hline & \multirow{2}{*}{ 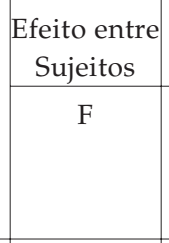 } & \multicolumn{4}{|c|}{ Parâmetros Estimados } & \multirow{2}{*}{$\begin{array}{l}\text { Efeito na renda }(\mathrm{R} \$) \text { da } \\
\text { mudança de uma uni- } \\
\text { dade da independente } \\
\text { com as demais constan- } \\
\text { tes, no nível da renda } \\
\text { média (R\$271) }\end{array}$} \\
\hline & & B & $\begin{array}{l}\text { Desvio } \\
\text { Padrão }\end{array}$ & $\mathrm{t}$ & Sig. & \\
\hline Modelo corrigido & 24,68 & & & & & \\
\hline Intercepto & 308,46 & 20,28 & 1,25 & 16,28 & 0,000 & \\
\hline Anos de estudo & 10,22 & 0,27 & 0,09 & 3,20 & 0,002 & 9,0 \\
\hline Pessoas no domicílio & 53,03 & $-1,66$ & 0,23 & $-7,28$ & 0,000 & $-51,9$ \\
\hline $\begin{array}{l}\text { Redes médias com so- } \\
\text { ciabilidade em igreja, } \\
\text { trabalho ou associações }\end{array}$ & 4,45 & 1,92 & 0,91 & 2,11 & 0,036 & 66,9 \\
\hline $\begin{array}{l}\text { Interação entre rendi- } \\
\text { mento estável e número } \\
\text { de nós }\end{array}$ & 13,77 & 0,04 & 0,01 & 3,11 & 0,002 & 1,3 \\
\hline $\begin{array}{l}\text { Interação entre segrega- } \\
\text { ção e número de esferas }\end{array}$ & 7,11 & 0,44 & 0,16 & 2,67 & 0,008 & 14,7 \\
\hline
\end{tabular}

Elaboração própria a partir de material empírico coletado.

Obs.: $\mathrm{N}=206$ casos; $\mathrm{R}^{2}$ de 0,427 e $\mathrm{R}^{2}$ ajustado de 0,409 . 
como seria de se esperar, indivíduos com escolaridade mais elevada tendem a ter renda maior. Cada ano de estudo acrescenta, em média, $\mathrm{R} \$ 9,0$ ao rendimento familiar médio per capita dos indivíduos (ver última coluna da tabela). Vale frisar que a análise inclui apenas indivíduos em situação de pobreza e, portanto, com variabilidade reduzida tanto na renda quanto na escolaridade. Seria possível que a realização do estudo com um leque mais amplo de grupos sociais resultasse em efeitos mais fortes da escolaridade.

A segunda variável, inversamente, afeta negativamente o rendimento - quanto maior o número de pessoas no domicílio, menor a renda per capita. O efeito do número de pessoas não é apenas numérico (embora essa variável entre no cálculo da variável dependente), visto que, no rendimento familiar total, estão incluídas rendas de outras pessoas que não o entrevistado, assim como as redes dão acesso a mais pessoas do que apenas ao ego. O que o modelo nos informa é que os efeitos de agregação das redes e das rendas não compensam o efeito de dependência e, à medida que cresce o número de pessoas em um domicílio, a dependência cresce mais rápido do que a entrada de outros geradores de renda e agregadores de redes. Como podemos observar na última coluna da tabela, cada indivíduo a mais no domicílio retira $\mathrm{R} \$ 51,9$ da renda, um efeito muito grande se considerarmos que cada ano de estudo a mais acrescenta $\mathrm{R} \$ 9,0$. Esse raciocínio é evidentemente hipotético e tem por objetivo apenas comparar o efeito relativo das diversas variáveis.

As variáveis relacionais entraram no modelo de três formas distintas. Em primeiro lugar, uma variável dicotômica que especifica a situação de o indivíduo ter ou não rede média com sociabilidade centrada em igreja, trabalho ou associações. Como vimos, essa situação corresponde a redes médias com sociabilidade variada, pouco homofílica e com baixo localismo. O efeito é positivo, indicando que a renda tende a ser mais elevada para indivíduos com esses padrões relacionais, acrescentando $\mathrm{R} \$ 66,9$ à renda, em média, o que corresponde a mais do que sete anos de estudo e ao efeito negativo de uma pessoa a mais no domicílio. Entretanto, temos que ter em mente que os tipos de rede e sociabilidade assumem apenas os valores zero e um, enquanto os anos de estudo variam entre zero e 12 anos, e as pessoas no domicílio, entre uma e nove ${ }^{23}$. 
O modelo também inclui duas variáveis de interação com dimensões relacionais. Em primeiro lugar, uma interação entre tamanho das redes e rendimento estável. O rendimento estável é capturado por uma variável dicotômica que ganha valor um nas situações de remuneração que garantam fluxos de rendimento mais ou menos regulares. Não se trata das condições analisadas anteriormente de trabalho ou trabalho protegido, já que estão englobadas todas as situações que podem gerar fluxo constante de rendimentos - trabalho com carteira, doméstico ou não, ser proprietário de negócio próprio, mas também ser aposentado. Entretanto, considerando o padrão de informalidade presente no mercado de trabalho local, e o fato de indivíduos permanecerem às vezes durante anos em empregos sem carteira, incluí ainda como com rendimento estável os empregados sem carteira, domésticos ou não, desde que estivessem nos seus atuais empregos há mais de um ano. Os indivíduos sem rendimento estável são os desempregados e as pessoas que afirmam viver de bicos, além dos sem carteira que estavam nos seus empregos há menos de um $a_{n o}^{24}$.

O sentido da interação é bastante fácil de entender. Uma variável de interação representa a multiplicação das variáveis envolvidas. Para cada caso, portanto, assumirá como valor a multiplicação dos valores de cada variável para aquele caso. Como "rendimento estável", assume o valor um para quem tem essa condição e zero para os demais; o termo de interação não tem efeito para quem não tem rendimento estável. Conforme podemos ver na última coluna, para os indivíduos que contam com rendimento estável, cada nó a mais acrescenta $\mathrm{R} \$ 1,3$ à renda. Como o número de nós varia entre quatro e 179, o efeito pode ser bastante significativo. Apenas para termos parâmetros de comparação, para quem tem rendimento estável, cada dez nós adicionais na rede correspondem a mais $R \$ 13,2$ na renda, um efeito superior a um ano adicional de estudo.

A última variável, por fim, também nos fornece uma interpretação bastante interessante, que complementa evidências já encontradas anteriormente. Trata-se de uma interação entre uma variável dicotômica correspondente à segregação e o número de esferas, indicador de variabilidade da sociabilidade. Como a segregação adquire valor zero em locais não segregados, a variabilidade da sociabilidade não tem efeitos sobre a renda naqueles locais, mas apenas nos segregados. Assim, para indivíduos que moram em locais segregados, cada esfera a mais na sua rede acrescenta $\mathrm{R} \$ 14,7$ à sua renda. Esse efeito é quase 
igual ao de dois anos de estudo adicionais, um impacto bastante significativo, considerando que o número de esferas varia entre um e sete. Esse resultado sugere que, em locais de maior isolamento espacial, a variabilidade da sociabilidade é importante para os rendimentos e, por meio deles, tem efeitos sobre o acesso a bens e serviços comprados no mercado. Para moradores de locais não segregados, o efeito não é significativo.

A interpretação da evidência é relativamente clara e segue a mesma direção de outros achados anteriores. Como a segregação espacial tende a causar isolamento social, estarão melhores entre os indivíduos segregados os que contarem com sociabilidade variada, indicando que as redes efetivamente podem ajudar a reduzir o isolamento causado pela segregação. Entretanto, como esse resultado é alcançado apenas para quem consegue manter padrões de sociabilidade variada, a situação social tende a ser pior para os indivíduos segregados que não conseguem manter padrões variados de sociabilidade, aumentando a heterogeneidade das situações. Por outro lado, entre os indivíduos que não estão submetidos ao isolamento da segregação, a variabilidade da sociabilidade não tem efeitos sobre a renda.

\section{SUMARIZANDO OS EFEITOS DAS REDES SOBRE 0 ACESSO A MERCADOS}

Vimos que as redes de indivíduos pobres tendem a ser menores, mais locais e a ter sociabilidade menos variada do que as de pessoas de classe média. Apesar disso, as redes também variam substancialmente dentro de cada grupo, e foi possível encontrar redes com características bastante distintas entre os pobres. O estudo demonstrou que essas diferenças têm importantes consequências para os indivíduos em termos de acesso a trabalho, trabalho protegido, precariedade social e rendimentos monetários.

Os tipos de rede e sociabilidade se associam fortemente à possibilidade de os indivíduos terem trabalho, terem trabalho que conte com algum grau de proteção e viverem em situações precárias. Em todos esses casos, a existência de padrões relacionais baseados em contatos primários e mais propensos à homofilia e ao localismo aparece associada a piores condições. Inversamente, quem conta com padrões de relação menos primários e mais associados a ambientes organizacionais tende, com maior frequência, a ter trabalho, ter trabalho mais protegido e a ser menos precário socialmente. Embora a mais importante condicio- 
nante das situações de precariedade seja esse tipo de sociabilidade pouco homofílica e pouco local, a precariedade é atenuada pela presença de sociabilidades centradas na família ou é agravada pelo status de migrante.

Por fim, a renda dos indivíduos está associada à sua escolaridade e à quantidade de pessoas residindo no domicílio, variáveis tradicionais da análise do tema, mas também ao tipo de padrão relacional dos indivíduos, ao tamanho das suas redes (para os indivíduos com fontes estáveis de rendimento), assim como à variabilidade da sociabilidade (para os indivíduos residentes em áreas segregadas). O tamanho dos efeitos dessas variáveis permite sustentar a destacada relevância das redes e da sociabilidade na explicação da renda dos mais pobres. Em todos os casos, são melhores as condições de indivíduos com redes médias, pouco locais e com sociabilidade construída em espaços organizacionais (igreja, trabalho e associações), que tendem a ser menos homofílicas.

Esses resultados confirmam a necessidade de incorporarmos simultaneamente as redes sociais e a segregação nos estudos sobre pobreza, a fim de ultrapassarmos as limitações impostas pelos paradigmas estruturalista e atomista da pobreza, e entendermos melhor os mecanismos associados à sua produção. A incorporação desses elementos contribui também, decisivamente, para a construção de políticas mais bem desenhadas para o combate ao problema.

(Recebido para publicação em novembro de 2008) (Versão definitiva em março de 2009) 


\section{As Redes Sociais Importam para a Pobreza Urbana?}

\section{NOTAS}

1. Um exemplo emblemático disso são os estudos desenvolvidos pelo Prime Minister's Strategy Unit, através da Social Exclusion Task Force, do governo britânico, e o Policy Research Initiative, do governo canadense. Disponíveis, respectivamente, em http://www.cabinetoffice.gov.uk/social_exclusion_task_force e em http://www. policyresearch.gc.ca.

2. Ou, tecnicamente, a apenas um passo do ego.

3. Relações homofílicas são relações entre pessoas de mesmo atributo.

4. A pesquisa incluiu também uma análise do papel das redes e da sociabilidade no acesso dos indivíduos a bens e serviços obtidos fora dos mercados (com as informações da pesquisa qualitativa), assim como uma investigação dos mecanismos relacionais que explicam tanto a diversidade das redes quanto a sua mediação das dinâmicas assinaladas (Marques, 2009).

5. Vale destacar que os resultados de um survey realizado em 2001 na Região Metropolitana de São Paulo, por Guimarães (2004), confirmam essa proeminência das redes $80 \%$ dos indivíduos que procuravam emprego afirmavam lançar mão de relações com familiares, amigos e conhecidos. Outro survey aplicado em 2004, também pela autora, indicou que, mesmo entre quem estava procurando emprego em agências, cerca de $60 \%$ afirmavam que o seu último trabalho fora obtido via rede (Guimarães, 2008).

6. Rigorosamente, portanto, não se trata de emprego, visto que os proprietários também estão incluídos nessa condição, mas considerei que, organizada dessa forma, a variável descreveria melhor a condição que gera efeitos sobre a pobreza. Ou seja, foi considerada a presença ou não de uma fonte de renda relativamente estável.

7. Apenas como exemplos dos tipos de ocupação nos quais os autônomos estavam engajados, tínhamos nove vendedores ambulantes, dois ajudantes de florista ocasionais, cinco carregadores de entulho ou de caminhão ocasionais e dois catadores de papel e de latas de alumínio.

8. Com, respectivamente, estatística F igual a 3,08 e p-value de 0,048, e estatística F igual a 6,95 e p-value de 0,001.

9. Para explorar o efeito dos tipos de rede e sociabilidade, construí um conjunto de tabelas cruzadas submetidas a testes estatísticos de variáveis nominais.

10. O método trabalha com tabelas de dupla entrada com as relações entre a variável dependente e cada preditora, testando todas as partições possíveis das suas categorias e escolhendo aquela que apresenta o maior valor para a estatística qui-quadrado. Os dados são agrupados segundo a partição escolhida e uma nova análise é realizada dentro de cada subgrupo, repetindo-se o procedimento anterior para a variável dependente e as demais preditoras. Esse processo é repetido sucessivamente até que os grupos divididos cheguem a um número mínimo de casos estipulado para a análise. Como se trata de um método de tipo stepwise, todas as combinações possíveis são analisadas e podemos tomar as variáveis indicadas no resultado final como representando os condicionantes mais importantes na explicação da variabilidade da variável dependente. Esse método foi escolhido, em vez de análises de regressão logística, por exemplo, pelo pequeno número de casos disponíveis. 
11. Relacionais: 1) número de nós da rede individual;2) grau médio;3) tamanho eficiente da rede egocentrada; 4) proporção de pessoas externas à área; 5) número total de esferas; 6) variáveis dicotômicas (dummy) referentes aos tipos de rede com cinco grupos; 7) variáveis dicotômicas referentes aos tipos de sociabilidade e rede, assim como às suas combinações. Socioeconômicas: 8) sexo do indivíduo; 9) anos de estudo; 10) renda familiar per capita; 11) frequenta igreja ou templo mais do que quinzenalmente. Etárias: 12) idade do indivíduo; 13) idoso (60 anos ou mais); 14) jovem (idade menor do que ou igual a 21 anos). Migratórias: 15) migrante; 16) migrante há mais de dez anos; 17) proporção de conterrâneos maior ou igual a 21\%. Espacial: 18) segregado. Nesse caso, as variáveis relativas ao trabalho foram excluídas por questões óbvias quem não tem trabalho não pode trabalhar fora, ter tempo de ocupação, emprego antigo ou ser classificado em determinada posição na ocupação.

12. Assim como no caso anterior, não se trata rigorosamente de condição de emprego. Ver nota 6.

13. Essa condição representava um subgrupo da analisada anteriormente, embora tenham sido retirados também seis casos para os quais não havia informações suficientes sobre proteção.

14. Todas as associações indicadas são representativas a $95 \%$ ou a $99 \%$ de confiabilidade.

15. Relacionais: 1) número de nós da rede individual;2) grau médio;3) tamanho eficiente da rede egocentrada; 4) proporção de pessoas externas à área; 5) número total de esferas; 6) variáveis dicotômicas (dummy) referentes aos tipos de rede com cinco grupos; 7) variáveis dicotômicas referentes aos tipos de sociabilidade e rede, assim como às suas combinações. Socioeconômicas: 8) sexo do indivíduo; 9) anos de estudo; 10) renda familiar per capita; 11) frequenta igreja ou templo mais do que quinzenalmente. Etárias: 12) idade do indivíduo; 13) idoso (60 anos ou mais); 14) jovem (idade menor do que ou igual a 21 anos). Migratórias: 15) migrante; 16) migrante há mais de dez anos; 17) proporção de conterrâneos maior do que ou igual a 21\%. Espacial: 18) segregado.

16. Em todas essas análises, as associações são significativas a $99 \%$ de confiabilidade.

17. Relacionais: 1) número de nós da rede individual; 2) grau médio; 3) tamanho eficiente da rede egocentrada; 4) proporção de pessoas externas à área; 5) número total de esferas; 6) variáveis dicotômicas (dummy) referentes aos tipos de rede com cinco grupos; 7) variáveis dicotômicas referentes aos tipos de sociabilidade e rede, assim como às suas combinações. Socioeconômicas: 8) anos de estudo;9) frequenta igreja ou templo mais do que quinzenalmente. Etárias: 10) idade do indivíduo; 11) idoso (60 anos ou mais); 12) jovem (idade menor do que ou igual a 21 anos). Migratórias: 13) migrante; 14) migrante há mais de dez anos; 15) proporção de conterrâneos maior do que ou igual a $21 \%$. Trabalho: 16) há quanto tempo está no trabalho atual; 17) trabalha fora da comunidade.

18. Obviamente, os seus rendimentos são muito superiores aos dos indivíduos em situação de pobreza e, como vimos, as suas redes também são muito distintas com relação ao tamanho, à variabilidade da sociabilidade e ao localismo. A inclusão da classe média atrapalharia os testes quantitativos por aumentar a variabilidade do fenômeno explicado sem que tivéssemos o necessário controle sobre o que ocorreria na vasta faixa que separa os dois grupos.

19. Em todas essas análises, as associações são significativas a $99 \%$ de confiabilidade. 
20. Esse tipo de modelo estatístico permite a análise da variabilidade de uma variável dependente contínua a partir do estudo tanto de variáveis categóricas (consideradas fatores) quanto contínuas (consideradas covariáveis). Quando as preditoras são todas variáveis categóricas, o modelo realiza uma Anova; quando as preditoras são todas variáveis contínuas, o modelo realiza uma análise de regressão; quando existe uma combinação de preditores categóricos e contínuos, realiza-se uma Ancova. O modelo assume a linearidade dos efeitos das variáveis independentes sobre a dependente, assim como a existência de igualdade de variâncias entre as variáveis independentes. A vantagem desse tipo de procedimento sobre a análise de regressão convencional está em que o procedimento considera os fatores como variáveis categóricas efetivamente, em vez de recodificá-las em uma ou mais variáveis dicotômicas. Agradeço a Edgard Fusaro a sugestão e a revisão das análises estatísticas realizadas aqui. Dadas as premissas de normalidade das variáveis dependente e de linearidade, utilizei como variáveis dependentes as raízes quadradas da renda e da renda familiar mensal per capita. Para melhorar a compreensão dos resultados, apresento os resultados convertidos para a renda familiar per capita em reais.

21. O modelo executa um teste específico para avaliar a violação da suposição de igualdade das variâncias das variáveis independentes. No nosso caso, a significância do teste de Levene foi de 0,195, rejeitando-se a hipótese de que as variâncias das variáveis independentes sejam diferentes e, portanto, levando à aceitação do modelo.

22. Três casos foram excluídos da análise por distarem mais de três desvios padrão dos valores esperados (casos 146, 153 e 237), resultando em 206 casos na análise.

23. É interessante acrescentar que a variabilidade da sociabilidade medida pelo número de esferas da rede também apresenta significância, mas apenas quando substitui os tipos de rede e sociabilidade citados, e acaba por retirar outras variáveis do modelo, reduzindo a explicação total.

24. O rendimento estável apresenta correlação significativa (e positiva) com a renda, mas a análise mostrou que um termo de interação de rendimento estável, com número de nós, também apresentava significância e aumentava a explicação do modelo, embora tornasse a variável original de rendimento estável não significativa. Dado o aumento da explicação, optei por manter a interação em vez da variável original. A consideração dos sem carteira como estáveis seguiu uma ótima sugestão de Nadya Guimarães. Além de especificar a condição ocupacional mais corretamente, tornou o modelo estatístico mais estável. 


\section{REFERÊNCIAS BIBLIOGRÁFICAS}

BIDART, Claire e LAVENU, Daniel. (2005), “Evolutions of Personal Networks and Life Events". Social Networks, vol. 27, no 4, pp. 359-376.

BLOKLAND, Talja. (2003), Urban Bonds. London, Basil Blackwell.

BRIGGS, Xavier de Souza. (2001), Ties that Bind, Bridge and Constrain: Social Capital and Segregation in the American Metropolis. Trabalho apresentado no seminário internacional Segregation in the City, Cambridge, Lincoln Institute for Land Policy, 26-28 de julho.

. (2003), Bridging Networks, Social Capital and Racial Segregation in America. Cambridge, KSG Faculty Research Working Paper Series.

. (2005), "Social Capital and Segregation in the United States", in D. P. Varady, Desegregating the City: Ghettos, Enclaves, and Inequality. Albany, NY, State University of New York Press.

CECHI, Claudio, MOLINAS, Luca e SABATINI, Fabio. (2008), “Is Social Capital a Policy Tool Against Poverty and Inequality? A Discussion of Development Strategies in Rural India", in E. Basile e I. Mukhopadhyay (eds.), Institutional Perspectives on Rural India. London/New York/Delhi, Anthem Press. Disponível em http:/ /www.social capitalgateway.org.

DUJISIN, Rodrigo A. e MAYA JARIEGO, Isidro. (2005), “Las Puentes Interlocales: Las Redes Personales de los Universitarios Alcalareños en Sevilla", in J. Porras e V. Espinoza (orgs.), Redes: Enfoque y Aplicaciones del Análisis de Redes Sociales (ARS). Santiago do Chile, Universidad Santiago de Chile/Universidad Bolivariana.

EMIRBAYER, Mustafa. (1997), "Manifesto for a Relational Sociology". American Journal of Sociology, vol. 103, no 2, pp. 281-317.

GUIMARÃES, Nadya. (2004), Transições Ocupacionais e Formas do Desemprego em São Paulo e Paris. Trabalho apresentado no seminário Estrutura Social e Segregação: São Paulo, Rio de Janeiro e Paris. São Paulo, Centro de Estudos da Metrópole/ Cebrap, 28-29 de junho.

. (2008), Como Sair do Desemprego? Laços Fortes e Laços Fracos na Procura de Trabalho em São Paulo. Trabalho apresentado no IX Encontro da Brazilian Studies Association (Brasa), New Orleans, Tulane University, 27-29 de março.

JARGOWSKY, Paul A. (1997), Poverty and Place: Ghettos, Barrios, and the American City. New York, Russel Sage.

LE GALÈS, Patrick. (1996), "Politiques Urbaines en Europe", in S. Paugam (org.), L'Exclusion: L'État des Savoirs. Paris, Éditions la Découverte.

LEVITAS, Ruth et alii. (2007), The Multi-Dimensional Analysis of Social Exclusion. Relatório de Pesquisa Social Exclusion Task Force, Department of Sociology and School for Social Policy, Townsend Centre for the International Study of Poverty e Bristol Institute for Public Affairs, University of Bristol. Disponível em http://www. cabinetoffice.gov.uk/social_exclusion_task_force. Acessado em julho de 2007.

LIN, Nan. (1999), "Social Networks and Status Attainment". Annual Review of Sociology, vol. 25, no 1, pp. 467-487. 


\section{As Redes Sociais Importam para a Pobreza Urbana?}

LOTTA, Gabriela S. (2006), Saber e Poder: Agentes Comunitários de Saúde Aproximando Saberes Locais e Políticas Públicas. Dissertação de mestrado, Fundação Getulio Vargas, São Paulo.

MARQUES, Eduardo. (2009), Redes Sociais, Segregação e Pobreza em São Paulo. São Paulo, Edusp.

e TORRES, Haroldo. (2005), São Paulo: Segregação, Pobreza e Desigualdades Sociais. São Paulo, Ed. Senac.

MASSEY, Douglas e DENTON, Nancy. (1993), American Apartheid: Segregation and the Making of the Underclass. Cambridge, Harvard University Press.

MAYA JARIEGO, Isidro. (2003), A General Typology of the Personal Networks of Immigrants with Less than 10 Years Living in Spain. Trabalho apresentado no XXIII Sunbelt International Social Network Conference, Cancún, 12-17 de fevereiro.

MINGIONE, Enzo. (1996), “Urban Poverty in the Advanced Industrial World: Concepts, Analysis and Debates", in E. Mingione, Urban Poverty and the Underclass. New York, Blackwell Publishers.

MOORE, Gwen. (1990), “Structural Determinants of Men's and Women's Personal Networks". American Sociological Review, vol. 55, no 2, pp. 726-735.

MOYA, Maria E. (2004), Repensando a Questão Social: Trajetórias de Algumas Interpretações nos Estados Unidos, França e Brasil. Dissertação de mestrado em Ciência Política, Universidade de São Paulo, São Paulo.

PAUGAM, Serge. (2005), Les Formes Élémentaires de la Pauvreté. Paris, PUF.

PAVEZ, Thais R. (2006), Políticas Públicas e Ampliação de Capital Social em Comunidades Segregadas: O Programa Santo André Mais Igual. Dissertação de mestrado em Ciência Política, Universidade de São Paulo, São Paulo.

PERRI 6. (1997), Escaping Poverty: From Safety Nets to Networks of Opportunity. London, Demos.

POLICY RESEARCH INITIATIVE. (2005a), Social Capital in Action. Governo federal do Canadá. Disponível em http://www.policyresearch.gc.ca/page.asp?pagenm= pub_index. Acessado em junho de 2007.

. (2005b), Social Capital as a Public Policy Tool. Governo federal do Canadá. Disponível em http:/ / www.policyresearch.gc.ca / page.asp?pagenm=pub_index. Acessado em junho de 2007.

PORTES, Alejandro. (1999), Migrações Internacionais: Origens, Tipos e Modos de Incorporação. Oeiras, Celta.

PUTNAM, Robert D. (1996), Comunidade e Democracia: A Experiência da Itália Moderna. Rio de Janeiro, Editora FGV.

SIMMEL, Georg. (1972) [1908], "El Cruce de los Círculos Sociales", in G. Simmel, Sociología. Estudios sobre las Formas de Socialización. Madrid, Alianza Universidad, vol. 2.

TILLY, Charles. (2001), "Mechanisms in Political Processes". Annual Review of Political Science, vol. 4, pp. 21-41.

. (2005), Identities, Boundaries and Social Ties. Boulder, CO, Paradigm. 


\section{Eduardo Cesar Leão Marques}

TORRES, Haroldo. (2005), "Políticas Sociais e Território: Uma Abordagem Metropolitana", in E. Marques e H. Torres (orgs.), São Paulo: Segregação, Pobreza e Desigualdades Sociais. São Paulo, Ed. Senac.

TROTTER, Robert T. (1999), "Friends, Relatives and Relevant Others: Conducting Ethnographic Network Studies", in J. J. Schensul et alii, Mapping Social Networks, Spatial Data, and Hidden Populations. London, Altamira.

WELLMAN, Barry. (2001), The Persistence and Transformation of Community: From Neighbourhood Groups to Social Networks. Relatório para Law Comission of Canada, Toronto. Disponível em http://www.chass.utoronto.ca/ wellman/publications/ lawcomm/lawcomm7.PDF. Acessado em junho de 2007.

WILSON, William J. (1987), The Truly Disadvantaged: The Inner City, the Underclass, and Public Policy. Chicago, University of Chicago Press. 


\section{ABSTRACT \\ Do Social Networks Matter for Urban Poverty?}

This article emphasizes the importance of social networks and sociability in situations of urban poverty. The study is based on research about social networks in contexts of urban poverty, identifying and analyzing networks of individuals in situations of poverty and subject to different types of segregation in the city, as compared to a control group of middle class individuals. The study adopted social network analysis as its methodology, in addition to exploratory and multivariate quantitative techniques. The results corroborate the central importance of sociability and of the social networks to which individuals belong in the definition of conditions surrounding employment, job stability, social vulnerability, and income. The multivariate analyses indicate that the networks are as important as traditional variables such as family structure and schooling.

Key words: urban poverty; social vulnerability; social networks; sociability; São Paulo

\section{RÉSUMÉ}

Les Réseaux Sociaux Influent-ils sur la Pauvreté Urbaine?

Dans cet article, on confirme l'importance des réseaux sociaux et de la sociabilité pour les situations de pauvreté urbaine. On part d'une recherche sur des réseaux sociaux dans des milieux de pauvreté urbaine, où l'on a repéré et analysé nombre d'individus en situation de pauvreté et vivant dans des conditions de ségrégation urbaine, ainsi que sur un groupe de contrôle constitué d'individus de la classe moyenne. On a utilisé des méthodes $\mathrm{d}^{\prime}$ analyse de réseaux sociaux, ainsi que des techniques quantitatives d'analyse exploratoire et multivariée. Selon les résultats, on peut soutenir qu'il est primordial de prendre en considération la sociabilité et les réseaux sociaux où se trouvent insérés les individus en vue de la définition des conditions d'emploi, d'emploi fixe, de vulnérabilité sociale et de revenus. Les analyses multivariées servent à montrer que les réseaux ont une importance aussi grande que la structure familiale et la scolarité.

Mots-clé: pauvreté urbaine; vulnérabilité sociale; réseaux sociaux; sociabilité; São Paulo (Brésil) 